CLINICAL STUDY

\title{
Studies of insulin resistance in patients with clinical and subclinical hyperthyroidism
}

\author{
Eirini Maratou ${ }^{1}$, Dimitrios J Hadjidakis ${ }^{2}$, Melpomeni Peppa ${ }^{2}$, Maria Alevizaki $^{3}$, Katerina Tsegka ${ }^{2}$, Vaia Lambadiari ${ }^{2}$, \\ Panayota Mitrou ${ }^{1}$, Eleni Boutati ${ }^{2}$, Anastasios Kollias ${ }^{2}$, Theofanis Economopoulos ${ }^{2}$, Sotirios A Raptis ${ }^{1,2}$ \\ and George Dimitriadis ${ }^{2}$ \\ ${ }^{1}$ Hellenic National Center for Research, Prevention and Treatment of Diabetes Mellitus and its Complications (HNDC), GR-10675 Athens, Greece, \\ ${ }^{2}$ Second Department of Internal Medicine, Research Institute and Diabetes Center, Attikon' University Hospital, Athens University, 1 Rimini Street, \\ GR-12462 Haidari, Greece and ${ }^{3}$ Endocrine Unit, Department of Clinical Therapeutics, Athens University, GR-11528 Athens, Greece \\ (Correspondence should be addressed to G Dimitriadis; Email: gdimi@ath.forthnet.gr,gdimitr@med.uoa.gr)
}

\begin{abstract}
Objective: Although clinical hyperthyroidism (HR) is associated with insulin resistance, the information on insulin action in subclinical hyperthyroidism (SHR) is limited.

Design and methods: To investigate this, we assessed the sensitivity of glucose metabolism to insulin in vivo (by an oral glucose tolerance test) and in vitro (by measuring insulin-stimulated rates of glucose transport in isolated monocytes) in 12 euthyroid subjects (EU), 16 patients with HR, and 10 patients with SHR.

Results: HR and SHR patients displayed higher postprandial glucose levels (area under the curve, $\mathrm{AUC}_{0-300} 32190 \pm 1067$ and $31497 \pm 716 \mathrm{mg} / \mathrm{dl}$ min respectively) versus EU (27 119 $\pm 1156 \mathrm{mg} / \mathrm{dl} \mathrm{min}, P<0.05)$. HR but not SHR patients displayed higher postprandial insulin levels $\left(\mathrm{AUC}_{0-300} 11020 \pm 985\right.$ and $9565 \pm 904 \mathrm{mU} / \mathrm{l}$ min respectively) compared with EU subjects $\left(\mathrm{AUC}_{0-300} 7588 \pm 743 \mathrm{mU} / \mathrm{l} \mathrm{min}, \mathrm{P}<0.05\right)$. Homeostasis model assessment index was increased in HR and SHR patients $(2.81 \pm 0.3$ and $2.43 \pm 0.38$ respectively) compared with EU subjects (1.27 $\pm 0.16, P<0.05)$, while Matsuda and Belfiore indices were decreased in HR $(4.21 \pm 0.41$ and $0.77 \pm 0.05$ respectively, $P<0.001)$ and SHR patients $(4.47 \pm 0.33$ and $0.85 \pm 0.05$ respectively, $P<0.05$ versus EU $(7.76 \pm 0.87$ and 1 respectively). At $100 \mu \mathrm{U} / \mathrm{ml}$ insulin, i) GLUT3 levels on the monocyte plasma membrane were increased in HR (468.8 \pm 7 mean fluorescence intensity (MFI)) and SHR patients $(522.2 \pm 25 \mathrm{MFI})$ compared with EU subjects $(407 \pm 18 \mathrm{MFI}, P<0.01$ and $P<0.05$ respectively), ii) glucose transport rates in monocytes (increases from baseline) were decreased in HR patients $(37.8 \pm 5 \%)$ versus EU subjects $(61.26 \pm 10 \%, P<0.05)$.

Conclusions: Insulin-stimulated glucose transport in isolated monocytes of patients with HR was decreased compared with EU subjects. Insulin resistance was comparable in patients with both HR and SHR.
\end{abstract}

European Journal of Endocrinology 163 625-630

\section{Introduction}

In clinical hyperthyroidism (HR), impaired glucose tolerance and inulin resistance are frequent findings (1-5). In HR, tissue metabolic rate increases significantly (1). To adapt to high energy demand, cellular rates of basal and insulin-stimulated glucose disposal are generally elevated to increase the rates of lactate formation and glucose oxidation; lactate is then used by the liver to increase the rates of gluconeogenesis and endogenous glucose production $(1,2)$.

Subclinical hyperthyroidism (SHR) is defined as decreased plasma TSH levels in the presence of normal levels of free thyroxine $\left(\mathrm{FT}_{4}\right)$ and free triiodothyronine $\left(\mathrm{FT}_{3}\right)$. SHR can be caused by exogenous or endogenous factors (6) and may be transient or persistent. The studies in the literature regarding insulin resistance in SHR are scarce and controversial. Insulin sensitivity in patients with iatrogenic SHR has been reported to be either reduced $(7,8)$ or unaltered $(9)$.

In SHR subjects, relevant changes in cardiovascular measures, such as arrhythmias, increased left ventricular mass, and impaired left ventricular mass function, have been recently reported; these changes are often accompanied by impaired diastolic function and, sometimes by reduced systolic performance on effort and decreased exercise tolerance, abnormalities that usually precede the onset of severe cardiovascular disease (10).

This study was undertaken in patients with HR and SHR to examine the sensitivity of glucose metabolism to insulin both in vivo (by an oral glucose tolerance test (OGTT) ) and in vitro (by measuring insulin-stimulated rates of glucose transport in isolated monocytes). 


\section{Materials and methods}

\section{Subjects}

The groups participating in the study were i) newly diagnosed clinical hyperthyroidism (HR) subjects with Graves' disease who received no treatment, ii) patients with SHR; these patients had autoimmune thyroiditis due to positive thyroid antibodies, and iii) euthyroid subjects (EU). There were no statistically significant differences in either body mass index or age between $\mathrm{EU}$ and HR and SHR groups $(P>0.05$, with one-way ANOVA). The characteristics and the hormonal and metabolic data of the groups are presented in Table 1. None of the subjects was receiving any treatment or had a family history of type 2 diabetes. The female participants were at the first half of their menstrual cycle, and no one was taking oral contraceptives. The duration of the disease, as reported by HR patients, was shorter than 3 months. Apart from tachycardia, perspiration, and tremor in some subjects, no other complication was present in HR patients. The duration of the SHR could not be accurately defined, as it is mostly asymptomatic. The normal ranges for hormones were $\mathrm{FT}_{3} 2.2-5.3 \mathrm{pg} / \mathrm{ml}, \mathrm{FT}_{4} 0.7-2.2 \mathrm{ng} / \mathrm{dl}$, $\mathrm{T}_{3} \quad 0.8-2.0 \mathrm{ng} / \mathrm{ml}, \mathrm{T}_{4} 5.1-14.1 \mu \mathrm{g} / \mathrm{dl}$, and $\mathrm{TSH}$ $0.27-4.2 \mu \mathrm{U} / \mathrm{ml}$. Anti-thyroglobulin (anti-TG) and anti-thyroperoxidase (anti-TPO) antibodies' reference ranges were $<34$ and $<115 \mathrm{U} / \mathrm{ml}$ respectively. EU subjects had negative anti-TG and anti-TPO antibodies $(10.9 \pm 5.3$ and $15.6 \pm 3.2 \mathrm{U} / \mathrm{ml}$ respectively), while these antibodies were positive in both HR $(231 \pm 83$ and $218 \pm 147 \mathrm{U} / \mathrm{ml}$ respectively) and SHR $(226 \pm 100$ and $213 \pm 103 \mathrm{U} / \mathrm{ml}$ respectively).

Some of the EU volunteers of the present study were used in a similar study published recently by our group (11). The protocol was approved by the hospital ethics committee, and subjects gave informed consent.

\section{Study protocol}

Subjects were admitted to the hospital at $0800 \mathrm{~h}$ after an overnight fast and received an OGTT (75 g glucose). Blood samples were drawn before the administration of glucose (at -30 and $0 \mathrm{~min}$ ) and at 15 - to $60-\mathrm{min}$ intervals for $300 \mathrm{~min}$ thereafter, and used for measurements of glucose (Yellow Springs Instrument, Yellow Springs, OH, USA) and insulin (RIA, Linco Research, St Charles, MO, USA).

In the fasting state, insulin resistance was estimated by the homeostasis model assessment index (HOMA, (fasting glucose $\times$ fasting insulin/22.5)) (12), while in the post-glucose state, insulin sensitivity was estimated by the Matsuda index (10 000/SQRT

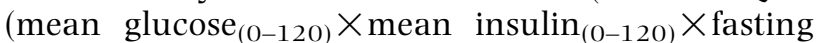
glucose $\times$ fasting insulin)) (13) and the Belfiore index $\left(2 /\left(\left(\right.\right.\right.$ GluAUC $_{(0-120)} /$ meanGluAUC $\left._{(0-120) E U}\right) \times$ $\left(\right.$ InsAUC $_{(0-120)} /$ MeanInsAUC $\left.\left._{(0-120) E U}\right)+1\right)(14)$.

At $-30 \mathrm{~min}, 20 \mathrm{ml}$ of blood were drawn for the isolation of mononuclear cells to assess i) GLUT3 and GLUT4 glucose transporter levels on the monocyte plasma membrane in response to insulin, and ii) insulin-stimulated rates of glucose transport.

\section{Effect of insulin on GLUT expression and 6-[N-(7-nitrobenz-2-oxa-1, 3-diazol-4-yl) aminol-6-deoxyglucose uptake: flow cytometry analysis}

Insulin exerts its action at a cellular level by numerous steps of intracellular mechanism, the insulin signaling pathway. Regarding glucose transport, the final step

Table 1 The characteristics, the clinical data, and the indices of insulin resistance of the groups involved in the study. Data are presented as mean values \pm S.E.M.

\begin{tabular}{|c|c|c|c|}
\hline & EU & HR & SHR \\
\hline Age (years) & $44 \pm 4.5$ & $44.25 \pm 2.9$ & $43.2 \pm 4$ \\
\hline Body mass index $\left(\mathrm{kg} / \mathrm{m}^{2}\right)$ & $24.28 \pm 0.47$ & $24.85 \pm 0.8$ & $24.6 \pm 1.26$ \\
\hline $\mathrm{FT}_{3}(\mathrm{pg} / \mathrm{ml})$ & $2.94 \pm 0.1$ & $9.28 \pm 1.1^{\ddagger}$ & $4.7 \pm 0.16$ \\
\hline $\mathrm{FT}_{4}(\mathrm{ng} / \mathrm{dl})$ & $1.23 \pm 0.07$ & $3.09 \pm 0.26^{\ddagger}$ & $1.83 \pm 0.137$ \\
\hline $\mathrm{T}_{3}(\mathrm{ng} / \mathrm{ml})$ & $1.3 \pm 0.06$ & $2.95 \pm 0.29^{\ddagger}$ & $1.54 \pm 0.12$ \\
\hline $\mathrm{T}_{4}(\mu \mathrm{g} / \mathrm{dl})$ & $8.13 \pm 0.3$ & $15.6 \pm 0.97^{\ddagger}$ & $10 \pm 0.96$ \\
\hline $\mathrm{TSH}(\mu \mathrm{U} / \mathrm{ml})$ & $1.9 \pm 0.4$ & $0.01 \pm 0.0005^{\ddagger}$ & $0.06 \pm 0.0035^{\ddagger}$ \\
\hline HDL cholesterol (mg/dl) & $50 \pm 10$ & $61.8 \pm 4.7$ & $58.6 \pm 2.34$ \\
\hline LDL cholesterol (mg/dl) & $137 \pm 10$ & $144.5 \pm 12.4$ & $140.8 \pm 7$ \\
\hline Triglycerides (mg/dl) & $82 \pm 10$ & $80.5 \pm 15.3$ & $83.7 \pm 8.12$ \\
\hline Systolic blood pressure $(\mathrm{mmHg})$ & $122 \pm 12$ & $130 \pm 14$ & $126 \pm 10$ \\
\hline Diastolic blood pressure $(\mathrm{mmHg})$ & $82 \pm 3$ & $86 \pm 2$ & $85 \pm 4$ \\
\hline HOMA index & $1.27 \pm 0.16$ & $2.81 \pm 0.3^{\dagger}$ & $2.43 \pm 0.38^{*}$ \\
\hline Matsuda index & $7.76 \pm 0.87$ & $4.21 \pm 0.41^{\ddagger}$ & $4.47 \pm 0.33^{\dagger}$ \\
\hline Belfiore index & 1 & $0.77 \pm 0.05^{\ddagger}$ & $0.85 \pm 0.05^{\star}$ \\
\hline Glucose $\mathrm{AUC}_{0-300}(\mathrm{mg} \mathrm{min} / \mathrm{dl})$ & $27119 \pm 1156$ & $32190 \pm 1067^{\dagger}$ & $31497 \pm 716^{*}$ \\
\hline Insulin $\mathrm{AUC}_{0-300}(\mathrm{mU} \mathrm{min} / \mathrm{l})$ & $7588 \pm 743$ & $11020 \pm 985^{\star}$ & $9565 \pm 904$ \\
\hline$n$ (number of females/males) & $12(8 / 4)$ & $16(12 / 4)$ & $10(7 / 3)$ \\
\hline
\end{tabular}

${ }^{\star} P<0.05,{ }^{\dagger} P<0.01,{ }^{\ddagger} P<0.001$. 
of insulin signaling is the enrichment of plasma membrane with GLUT3 and GLUT4 isoforms. Surface glucose transporter isoforms were determined after incubating cells with insulin and staining them with anti-GLUT antisera. In summary, mononuclear cells were aliquoted at the desired concentration $\left(1 \times 10^{6} \mathrm{cells} / \mathrm{ml}\right)$ and incubated for $60 \mathrm{~min}$, at $22^{\circ} \mathrm{C}$, in a buffer $(\mathrm{NaCl} 140 \mathrm{mM}$, HEPES $20 \mathrm{mM}$, KCl $5 \mathrm{mM}$, $\mathrm{MgSO}_{4} 2.5 \mathrm{mM}$, and glucose $5.5 \mathrm{mM}$, pH 7.4), containing different concentrations of insulin (Sigma Diagnostics). Termination of incubation was achieved with the addition of cytochalasin-B (10 $\mathrm{M}$; Sigma Diagnostics). Cells were then stained with specific antiserum for GLUT3 and GLUT4, and were analyzed by flow cytometry as described previously in detail (15).

For the glucose transport experiments, the tracer used to monitor glucose flux in monocytes was 6-[N-(7-nitrobenz-2-oxa-1, 3-diazol-4-yl) amino]-6deoxyglucose (NBDG, Invitrogen). Cells were suspended in the above-mentioned buffer at the same concentration. Flow cytometric analysis was initiated immediately after the addition of NBDG (final concentration $30 \mu \mathrm{M})$ and insulin. The uptake of the fluorescent probe was recorded as mean fluorescence intensity (MFI) during a $500 \mathrm{~s}$ interval, when the reaction reached a plateau (15).

\section{Statistical analysis}

Grouped data are expressed as mean \pm s.E.M. 6-NBDG uptake is presented as an increase over baseline (MFI of cells prior to the addition of the fluorescent analog). The statistical analysis was performed by the statistic software GraphPad InStat (San Diego, CA, USA). The normal distribution of the data was verified by the Kolmogorov and Smirnov method. Insulin doseresponse curves were analyzed with repeated-measures ANOVA. Comparison between groups was performed by one-way ANOVA with Bonferroni's post hoc test.

\section{Results}

Postprandial plasma insulin levels were increased in HR patients compared with EU subjects $(P<0.05)$. Postprandial plasma glucose levels were higher in both HR and SHR patients compared with EU $(P<0.01$ and $P<0.05$ respectively; Fig. 1$)$.

HOMA index reflects the insulin resistance in the fasting state, while Matsuda and Belfiore indices reflect insulin sensitivity in the postprandial state.

HOMA index was increased in both HR $(2.81 \pm 0.3)$ and SHR patients $(2.43 \pm 0.38)$ compared with EU subjects $(1.27 \pm 0.16, P<0.01$ and $P<0.05$ respectively). Belfiore and Matsuda indices were decreased in both HR $(0.77 \pm 0.05$ and $4.21 \pm 0.41$ respectively $)$ and SHR (0.82 \pm 0.04 and $4.47 \pm 0.33$ respectively)
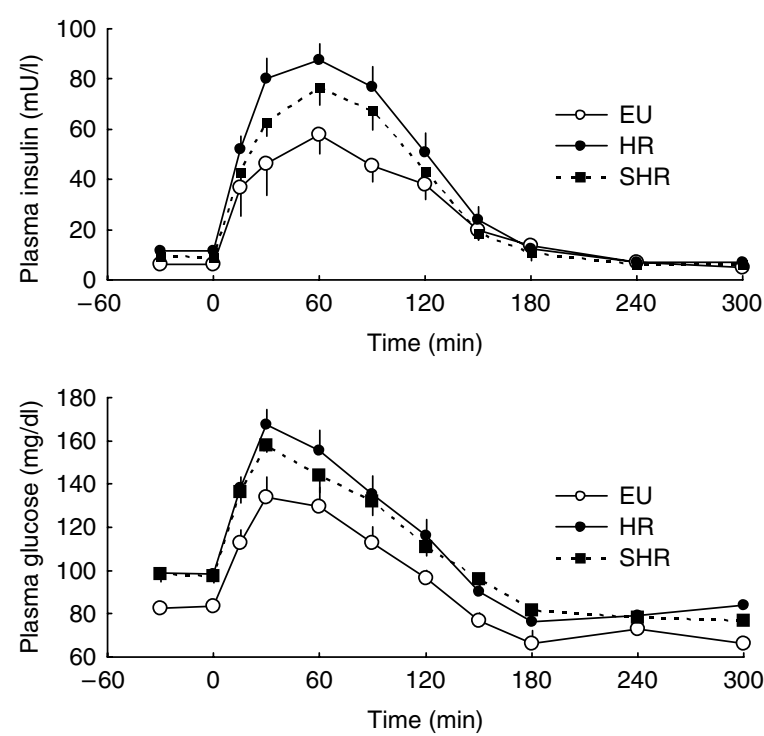

Figure 1 Plasma glucose (A) and insulin (B) levels in euthyroid (EU) subjects, and patients with clinical hyperthyroidism (HR) and subclinical hyperthyroidism (SHR) after an OGTT; postprandial plasma insulin levels were increased in patients with $\mathrm{HR}$ versus EU subjects $(P<0.05)$. Postprandial plasma glucose levels were higher in both HR and SHR patients compared with EU subjects $(P<0.01$ and $P<0.05$ respectively).

patients compared with EU (1 $\kappa \alpha$ l $7.76 \pm 0.87$, $P<0.001$ and $P<0.01$ respectively).

In monocytes from EU subjects, when insulin was increased from 0 to $100 \mu \mathrm{U} / \mathrm{ml}$, GLUT4 and GLUT3 isoforms on the plasma membrane increased by $39 \%$ (from 194 to $270 \mathrm{MFI}$ ) and by $34 \%$ (from 301 to $403 \mathrm{MFI}$ ) respectively $(P<0.0001$ with ANOVA for both). The respective increases for the HR patients was $13 \%$ (from 318 to 360 MFI, $P=0.001$ with ANOVA) and $21 \%$ (from 388 to 469 MFI, $P<0.0001$ with ANOVA), while the respective increases for the SHR patients was $12 \%$ (from 252 to 309 MFI, $P=0.049$ with ANOVA) and $22.8 \%$ (from 466 to 522 MFI, $P=0.021$ with ANOVA; Fig. 2).

At $100 \mu \mathrm{U} / \mathrm{ml}$ insulin, GLUT4 levels on the monocyte plasma membrane increased in the $\mathrm{HR}$ patients (360 MFI) versus EU subjects (270 MFI, $P<0.05)$, while GLUT3 levels increased in both HR (403 MFI) and SHR patients (522 MFI) compared with EU subjects (403 MFI, $P<0.05$; Fig. 2).

In monocytes from EU subjects, the 6-NBDG uptake (increases from baseline) in the presence of 0,25 , and $100 \mu \mathrm{U} / \mathrm{ml}$ insulin was increased by 19,43 , and $62 \%$ respectively $(P<0.005$; Fig. 3$)$. The respective increases for $\mathrm{HR}$ patients were 26,34 , and $37.8 \%(P<0.001)$, while the respective increases for SHR patients were 29.6, 36, and 49.5\% ( $P<0.001$; Fig. 3).

At $100 \mu \mathrm{U} / \mathrm{ml}$ insulin, the 6-NBDG uptake in monocytes from HR patients was decreased compared with EU subjects $(P<0.05$, Fig. 3), while there was no significant change in the monocytes isolated from SHR patients. 

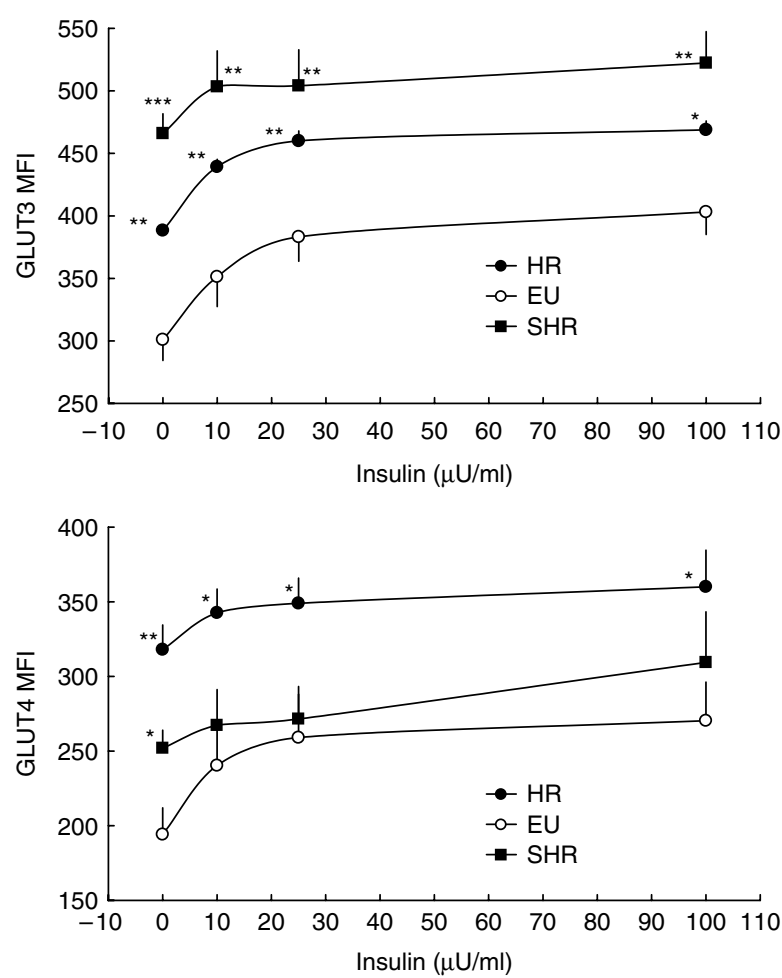

Figure 2 Plasma membrane levels of GLUT4 (A) and GLUT3 (B) in isolated monocytes in the presence of physiological concentrations of insulin in euthyroid (EU) subjects, and patients with clinical hyperthyroidism (HR) and subclinical hyperthyroidism (SHR); ${ }^{\star} P<0.05,{ }^{\star \star} P<0.01$ versus EU.

\section{Discussion}

Our results demonstrate the presence of insulin resistance not only in HR but also in SHR patients. Increased HOMA and decreased Matsuda and Belfiore indices in HR and SHR patients compared with euthyroid subjects suggest that insulin resistance is present in both fasting and post-glucose state. Our results are in agreement with those of Yavuz et al. $(7,8)$ reporting significantly lower insulin sensitivity in a group of SHR. Interestingly, recent studies have shown that even subtle decreases in the levels of thyroid hormones within the physiological range negatively correlate with the HOMA index (16). These findings, taken together with the results of the present study, suggest that even small deviances from thyroid hormone equilibrium may eventually lead to insulin resistance.

Monocytes provide an easily accessible and reliable model for metabolic studies. These cells have insulin receptors that quickly respond to changes in insulin concentrations and, in the presence of insulin rapidly increase their rates of glucose disposal $(15,17,18)$. Moreover, monocytes express all GLUT isoforms found in muscle and adipose tissue, and the increases in glucose transport in response to insulin in these cells correspond well with those observed in tissues quantitatively important for glucose disposal $(15,19)$. We have previously used monocytes as a cellular model to study insulin sensitivity $(11,15)$; furthermore, we have suggested the important role of GLUT3 in compensating increased tissue demand for glucose in the HR state $(20,21)$.

Our data show an elevated basal abundance of GLUT4 and GLUT3 in HR and SHR patients. This is consistent with previous studies on HR patients $(20,21)$. The increment of expression of GLUT3 and GLUT4 glucose transporters at the basal level of insulin reflects the adaptation of the monocyte to cope with the increased metabolic rates involved in this condition.

In monocytes isolated from HR patients, maximal insulin levels induced an increased GLUT3 and GLUT4 abundance on the monocyte plasma membrane compared with EU subjects; the response in the monocytes isolated from SHR patients was intermediate to that of HR patients and EU subjects (Fig. 2). GLUT3 is not the main insulin-regulated transporter in tissues, but as has been shown $(22,23)$, the expression of this isoform increases several fold in metabolic stress and increased tissue energy demand; under these conditions, this glucose transporter becomes primarily responsible for the increase in cellular glucose transport and utilization.

Glucose transport controls the rate of glucose utilization and is therefore an important regulatory step in cell metabolism (24). In HR, the absolute rates of insulin-stimulated glucose transport in peripheral tissues (such as muscle or adipose tissue) have generally been found to be normal or increased, in order to adapt to high energy demand $(3,25)$. However, we have recently shown that glucose uptake in muscle in HR is indeed resistant to insulin, but this defect is masked by a marked increase in blood flow (4); this could be attributed to the dramatic decrease in intracellular pathways of insulin-stimulated glucose metabolism

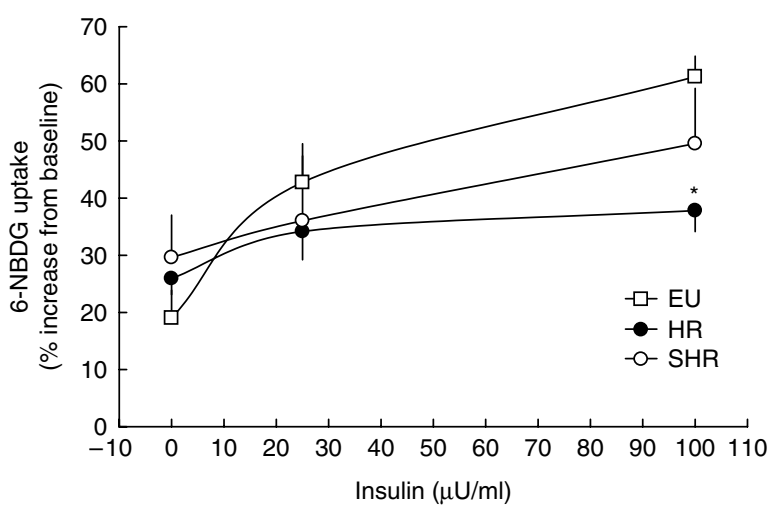

Figure 3 Transport rates of glucose analog (6-NBDG) in isolated monocytes in the presence of physiological concentrations of insulin in euthyroid (EU) subjects, and patients with clinical hyperthyroidism (HR) and subclinical hyperthyroidism (SHR); ${ }^{\star} P<0.05$ versus EU. 6-NBDG uptake is presented as an increase over baseline (MFI of cells prior to 6-NBDG addition). 
(such as glycogen synthesis) $(25,26)$. In addition, tumor necrosis factor $\alpha$ and interleukin 6 may contribute to insulin resistance in the metabolism of both lipids and glucose in HR (27). These findings support the results of the present study: in HR patients, glucose uptake in monocytes in the presence of insulin was significantly decreased compared to euthyroid subjects; the SHR group showed an intermediate response suggesting that $\mathrm{SHR}$ is an intermediate metabolic condition between EU and HR (which is further supported by the intermediate levels of the thyroid hormones in our SHR group). This result comes in striking contrast with the significantly increased abundance of insulin-stimulated GLUT3 and GLUT4 glucose transporters observed in monocytes isolated from HR and SHR patients. The lack of correlation between the abundance of GLUT3 and GLUT4 and the insulin-stimulated glucose uptake in the monocytes of the HR patients could be attributed to elevated intracellular concentration of calcium. It has been recently shown that the elevated levels of $\mathrm{T}_{3}$ in HR increase calcium concentration in the cytosol (28). Elevated levels of cytosolic calcium can modulate insulin's ability to desphosporylate GLUT4, thus reducing its intrinsic activity and resulting in calciuminduced insulin resistance (29).

In conclusion, HR and SHR are both states of insulin resistance. Both insulin resistance and the increased abundance of GLUT3 and GLUT4, on monocyte plasma membrane of SHR, which were found intermediate to those of HR and EU, are likely explained by the different degrees of thyroid hormone levels. Future research should focus on the insulin signaling cascade and the plausible association of impairment of phosphorylation pattern of signaling molecules (such as insulin receptor substrate 1) with decreased glucose uptake.

\section{Declaration of interest}

The authors declare that there is no conflict of interest that could be perceived as prejudicing the impartiality of the research reported.

\section{Funding}

This project has been co-funded by the European Social Fund and National Resources - (EPEAEK II) PYTHAGORAS II.

\section{Acknowledgements}

We thank E Pappas for technical support and V Fragaki, R N for nursing assistance.

\section{References}

1 Dimitriadis G \& Raptis S. Thyroid hormone excess and glucose intolerance. Experimental and Clinical Endocrinology and Diabetes 2001109 (Suppl 2) S225-S239. (doi:10.1055/s-2001-18584)

2 Dimitriadis G, Baker B, Marsh M, Mandarino L, Rizza R, Bergman R, Haymond M \& Gerich J. Effect of thyroid hormone excess on action, secretion and metabolism of insulin in humans. American Journal of Physiology. Endocrinology and Metabolism 1985 248 593-601.

3 Dimitriadis G, Mitrou P, Lambadiari V, Boutati E, Maratou E, Koukkou E, Tzanella M, Thalassinos N \& Raptis SA. Glucose and lipid fluxes in the adipose tissue after meal ingestion in hyperthyroidism. Journal of Clinical Endocrinology and Metabolism 200691 1112-1118. (doi:10.1210/jc.2005-0960)

4 Dimitriadis G, Mitrou P, Lambadiari V, Boutati E, Maratou E, Koukkou E, Panagiotakos D, Tountas N, Economopoulos T \& Raptis SA. Insulin-stimulated rates of glucose uptake in muscle in hyperthyroidism: the importance of blood flow. Journal of Clinical Endocrinology and Metabolism 200893 2413-2415. (doi:10.1210/jc.2007-2832)

5 Caixàs A, Tirado R, Vendrell J, Gallart L, Megía A, Simón I, Llauradó G, González-Clemente JM \& Giménez-Palop O. Plasma visfatin concentrations increase in both hyper and hypothyroid subjects after normalization of thyroid function and are not related to insulin resistance, anthropometric or inflammatory parameters. Clinical Endocrinology 200971 733-738. (doi:10.1111/j.13652265.2009.03546.x)

6 Ross DS. Subclinical thyrotoxicosis. In Werner and Ingbar's The Thyroid: A Fundamental and Clinical Text, pp 1016-1020, 8th edn. Eds LE Bravermen \& RD Utiger. Philadelphia: Lippincott Williams and Wilkins, 2000.

7 Yavuz DG, Yüksel M, Deyneli O, Ozen Y, Aydin H \& Akalin S. Association of serum paraoxonase activity with insulin sensitivity and oxidative stress in hyperthyroid and TSH-suppressed nodular goitre patients. Clinical Endocrinology 200461 515-521. (doi:10. 1111/j.1365-2265.2004.02123.x)

8 Yavuz DG, Yazici D, Toprak A, Deyneli O, Aydin H, Yüksel M \& Akalin S. Exogenous subclinical hyperthyroidism impairs endothelial function in nodular goiter patients. Thyroid $2008 \mathbf{1 8}$ 395-400. (doi:10.1089/thy.2007.0299)

9 Heemstra KA, Smit JW, Eustatia-Rutten CF, Heijboer AC, Frölich M, Romijn JA \& Corssmit EP. Glucose tolerance and lipid profile in longterm exogenous subclinical hyperthyroidism and the effects of restoration of euthyroidism, a randomised controlled trial. Clinical Endocrinology 200665 737-744. (doi:10.1111/j.1365-2265. 2006.02660.x)

10 Biondi B, Palmieri EA, Klain M, Schlumberger M, Filetti S \& Lombardi G. Subclinical hyperthyroidism: clinical features and treatment options. European Journal of Endocrinology 2005 152 1-9. (doi:10.1530/eje.1.01809)

11 Maratou E, Hadjidakis DJ, Kollias A, Tsegka K, Peppa M, Alevizaki M, Mitrou P, Lambadiari V, Boutati E, Nikzas D, Tountas N, Economopoulos T, Raptis SA \& Dimitriadis G. Studies of insulin resistance in patients with clinical and subclinical hypothyroidism. European Journal of Endocrinology $2009160785-$ 790. (doi:10.1530/EJE-08-0797)

12 Matthews DR, Hosker JP, Rudenski AS, Naylor BA, Treacher DF \& Turner RC. Homeostasis model assessment: insulin resistance and beta-cell function from fasting plasma glucose and insulin concentrations in man. Diabetologia 198528 412-419. (doi:10. 1007/BF00280883)

13 Matsuda M \& DeFronzo RA. Insulin sensitivity indices obtained from oral glucose tolerance testing: comparison with the euglycemic insulin clamp. Diabetes Care 199922 1462-1470. (doi:10.2337/diacare.22.9.1462)

14 Belfiore F, Iannello S \& Volpicelli G. Insulin sensitivity indices calculated from basal and OGTT-induced insulin, glucose, and FFA levels. Molecular Genetics and Metabolism 199863 134-141. (doi:10.1006/mgme.1997.2658)

15 Dimitriadis G, Maratou E, Boutati E, Psarra K, Papasteriades C \& Raptis SA. Evaluation of glucose transport and its regulation by insulin in human monocytes using flow cytometry. Cytometry. Part A 200564 27-33. (doi:10.1002/cyto.a.20108)

16 Roos A, Bakker SJ, Links TP, Gans RO \& Wolffenbuttel BH. Thyroid function is associated with components of the metabolic syndrome in euthyroid subjects. Journal of Clinical Endocrinology and Metabolism 200792 491-496. (doi:10.1210/jc.2006-1718) 
17 Beck-Nielsen H \& Pedersen O. Insulin binding, insulin degradation and glucose metabolism in human monocytes. Diabetologia 1979 17 77-84. (doi:10.1007/BF01222206)

18 Bieger W, Weicker H \& Michl J. Transport and utilization of amino acids and glucose in human monocytes: activation of glucose metabolism by insulin. Journal of Clinical Endocrinology and Metabolism 198050 1121-1126. (doi:10.1210/jcem-50-61121)

19 Estrada E, Elliott E, Zinman B, Poon I, Liu Z, Klip A \& Daneman D. Regulation of glucose transport and expression of GLUT3 transporters in human circulating mononuclear cells: studies in cells from insulin-dependent and nondiabetic individuals. Metabolism $1994 \quad 43 \quad 591-598 . \quad$ (doi:10.1016/00260495(94)90201-1)

20 Dimitriadis G, Maratou E, Boutati E, Kollias A, Tsegka K, Alevizaki M, Peppa M, Raptis SA \& Hadjidakis DJ. IGF-I increases the recruitment of GLUT4 and GLUT3 glucose transporters on cell surface in hyperthyroidism. European Journal of Endocrinology 2008158 361-366. (doi:10.1530/EJE-07-0532)

21 Dimitriadis G, Maratou E, Alevizaki M, Boutati E, Psara K, Papasteriades C \& Raptis SA. Thyroid hormone excess increases basal and insulin-stimulated recruitment of GLUT3 glucose transporters on cell surface. Hormone and Metabolic Research 200537 15-20. (doi:10.1055/s-2005-861026)

22 Khayat ZA, McCall AL \& Klip A. Unique mechanism of GLUT3 glucose transporter regulation by prolonged energy demand: increased protein half-life. Biochemical Journal 19981 713-718.

23 Macheda ML, Rogers S \& Best JD. Molecular and cellular regulation of glucose transporter (GLUT) proteins in cancer. Journal of Cellular Physiology 2005202 654-662. (doi:10.1002/ jcp.20166)
24 Shepherd PR \& Kahn BB. Glucose transporters and insulin action - implications for insulin resistance and diabetes mellitus. New England Journal of Medicine 1999341 248-257. (doi:10. 1056/NEJM199907223410406)

25 Dimitriadis G, Parry-Billings M, Bevan S, Leighton B, Krause U, Piva T, Challiss J, Wegener G \& Newsholme E. The effects of insulin on transport and metabolism of glucose in skeletal muscle from hyperthyroid and hypothyroid rats. European Journal of Clinical Investigation $1997 \quad 27$ 475-483. (doi:10.1046/j.1365-2362. 1997.1380688.x)

26 Dimitriadis GD, Leighton B, Vlachonikolis IG, Parry-Billings M, Challiss RA, West D \& Newsholme EA. Effects of hyperthyroidism on the sensitivity of glycolysis and glycogen synthesis to insulin in the soleus muscle of the rat. Biochemical Journal 1988253 87-92.

27 Mitrou P, Boutati E, Lambadiari V, Tsegka A, Raptis AE, Tountas N, Economopoulos T, Raptis SA \& Dimitriadis G. Insulin resistance in hyperthyroidism: the role of IL6 and TNF alpha. European Journal of Endocrinology 2010162 121-126. (doi:10.1530/EJE-09-0622)

28 Wang YG, Dedkova EN, Fiening JP, Ojamaa K, Blatter LA \& Lipsius SL. Acute exposure to thyroid hormone increases $\mathrm{Na}^{+}$ current and intracellular $\mathrm{Ca}^{2+}$ in cat atrial myocytes. Journal of Physiology 2003546 491-499. (doi:10.1113/jphysiol.2002. 032847)

29 Begum N, Leitner W, Reusch JE, Sussman KE \& Draznin B. GLUT-4 phosphorylation and its intrinsic activity. Mechanism of $\mathrm{Ca}(2+)-$ induced inhibition of insulin-stimulated glucose transport. Journal of Biological Chemistry 199315 3352-3356.

Received 25 May 2010

Accepted 19 July 2010 